\title{
Role of Composition on Polymerization Shrinkage and Shrinkage Stress in Dental Composites
}

\author{
Anand V Susila
}

\begin{abstract}
Polymer-based dental composites are the widely used direct restorative materials. However, one of the disadvantages that include polymerization shrinkage, which leads to a cascade of effects like shrinkage stress, cusp deflection, enamel/dentinal cracks, marginal leakage, marginal discoloration, secondary caries, and postoperative sensitivity, needs eradication to improvise their performance. Polymerization shrinkage is the result of covalent bonds replacing van der Waals forces in a polymer. Many factors play a significant role in the polymerization shrinkage development, its magnitude, and the shrinkage stress. Viscosity, glass transition temperature, density, reaction kinetics, molecular mobility, modulus development, gel point, vitrification, degree of conversion, configuration (C) factor, and compliance of bonded surfaces dictate both the quantum of shrinkage and when it occurs and if and how its stresses are relieved. There are three efficient methods of reducing polymerization shrinkage and shrinkage stress. The first one focuses on reducing the reactive groups, the second one focuses on introducing new chemistries, and the third method focuses on controlling curing protocols. Increasing the molar volume and molecular weight of resins helps reduce reactive groups as is increasing the filler content. Alternative polymerization methods like ring-opening polymerization and stepgrowth polymerization have been very effective ways of reducing shrinkage. Debonding the fillers or using functionalized fillers or using different coupling agents based on chain transfer and dynamic covalent chemistry (DCC) are promising methods to relieve shrinkage stress. Modifying the available methacrylates; introducing certain chemicals; altering solvents, inhibitors, initiators, and coinitiators; using bulk-fill concept; and utilizing ormocer technology are also catching up with moderate to immense potential to reduce either shrinkage or shrinkage stress. Among filler modifications, nanogel incorporation, among matrix modifications, thiocarbonate and allyl sulfide introduction and among coupling agent modifications, using functionalized agents seem to be the best methods in either reducing shrinkage or shrinkage stress. Though laboratory investigations have been very much encouraging the above-mentioned methods, the real test of clinical studies is not as optimistic. Long-term clinical performance of materials based on these various methods has not been clinically significantly different from conventional materials. Nonetheless, some of the new materials have not yet gone through the rigor of long-term clinical studies and hence controlled clinical trials of such materials are highly recommended.
\end{abstract}

Keywords: Bulk-fill composites, Composite resin, Methacrylates, Ormocers, Polymerization shrinkage, Shrinkage stress, Silorane, Thiol-ene. Journal of Operative Dentistry and Endodontics (2021): 10.5005/jp-journals-10047-0106

\section{INTRODUCTION}

Dental composites have been rehabilitating many teeth and smiles since their inception seven decades back. Ever since the introduction of acid-etching by Michael Buonocore in 1955 and Bisphenol A diglycidyl methacrylate (BisGMA) resin by Bowen in 1960, composites have been the most popular direct aesthetic restorative materials available to dentists.

Polymerization shrinkage is defined as the volumetric contraction of polymers as opposed to monomers upon polymerization reaction that hardens the resin. In general and also in dental composites, it is caused by the replacement of loose van der Waals bonds in the monomeric resin by the compact covalent bonds in a polymeric resin. In conventional and contemporary composites, it ranges between 1 and 6\%. ${ }^{1}$ Conventional composites utilize free-radical addition polymerization (Fig. 1), and methacrylate chemistry is the most often utilized in resin (Fig. 2). Even though ormocers were introduced to reduce shrinkage, they too polymerize by free-radical polymerization. The three popular methods of reducing shrinkage are as follows:

\section{(I) Reducing reactive sites}

A) By increasing molecular weight/unit volume of resin/ reducing double-bond concentration of resins

B) By increasing filler

(II) Introducing new chemistries
Department of Conservative Dentistry and Endodontics, Madha Dental College and Hospital, Chennai, Tamil Nadu, India

Corresponding Author: Anand V Susila, Department of Conservative Dentistry and Endodontics, Madha Dental College and Hospital, Chennai, Tamil Nadu, India, Phone: +91 7550022397, e-mail: drsusila2000@gmail.com

How to cite this article: Susila AV. Role of Composition on Polymerization Shrinkage and Shrinkage Stress in Dental Composites. J Oper Dent Endod 2021;6(1):31-44.

Source of support: Nil

Conflict of interest: None

A) Alternative polymerization techniques

1) Ring-opening polymerization

a) Liquid crystalline monomers (Fig. 3)

b) Vinyl cyclopropane (Fig. 4)

c) Spiro-orthocarbonate (Fig. 5)

d) Siloranes (Fig. 6)

2) Step-growth polymerization
a) Thiol-Michael
b) Thio-urethanes
c) Thiol-ene
d) Thio-carbonate

() The Author(s). 2021 Open Access This article is distributed under the terms of the Creative Commons Attribution 4.0 International License (https://creativecommons. org/licenses/by-nc/4.0/), which permits unrestricted use, distribution, and non-commercial reproduction in any medium, provided you give appropriate credit to the original author(s) and the source, provide a link to the Creative Commons license, and indicate if changes were made. The Creative Commons Public Domain Dedication waiver (http://creativecommons.org/publicdomain/zero/1.0/) applies to the data made available in this article, unless otherwise stated. 
Initiation<smiles>[R]OC(=O)C(=C)C</smiles>

$\mathrm{R}$

Propagation<smiles>[R]OC(=O)[C](C)C[Al]C</smiles><smiles>[R]OC(=O)[C](C)CC(C)(C)C(=O)O[R]</smiles>

Fig. 1: Free-radical addition polymerization (Source: From Weinmann W, Thalacker C, Guggenberger R. Siloranes in dental composites. Dent Mater 2005;21(1):68-74. DOI: 10.1016/j.dental.2004.10.007.)<smiles>C=C(C)C(=O)OCC(O)COc1ccc(C(C)(C)c2ccc(OCC(O)COC(=O)C(=C)C)cc2)cc1</smiles><smiles>C=C(C)C(=O)OCCOC(=O)N(C)CCC(C)CC(C)(C)CCN(C)C(=O)OCCOC(=O)C(=C)C</smiles><smiles>C=C(C)C(=O)COCCOCCOC(=O)C(=C)C</smiles>

Fig. 2: Commonly used dimethacrylates in dental composites (Source: From Charton C, FalkV, Marchal P, et al. Influence of $T_{\mathrm{g}}$, viscosity and chemical structure of monomers on shrinkage stress in light-cured dimethacrylate-based dental resins. Dent Mater 2007;23(11):1447-1459. DOI: 10.1016/j. dental.2007.05.017.)

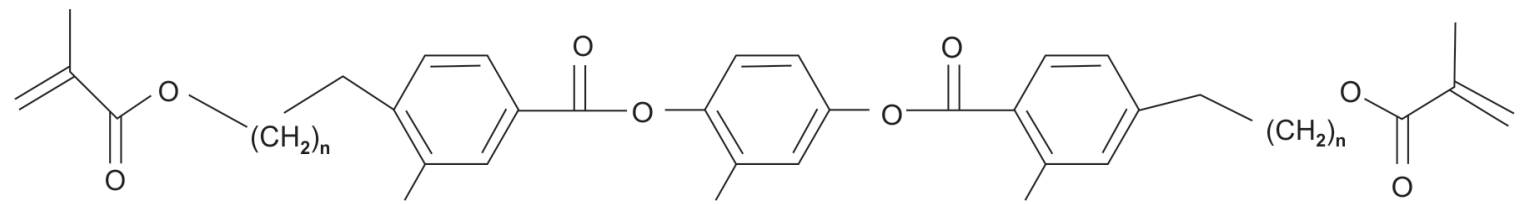

Fig. 3: Liquid crystal monomer (Source: From Weinmann W, Thalacker C, Guggenberger R. Siloranes in dental composites. Dent Mater 2005;21(1): 68-74. DOI: 10.1016/j.dental.2004.10.007.) 


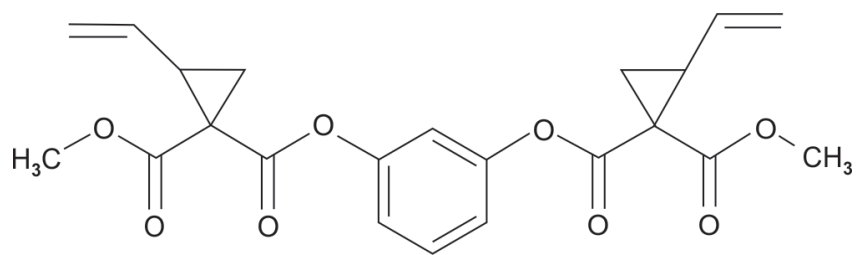

Fig. 4:Vinyl cyclopropane (Source: From Weinmann W, Thalacker C, Guggenberger R. Siloranes in dental composites. Dent Mater 2005;21(1):68-74. DOI: $10.1016 /$ j.dental.2004.10.007.)
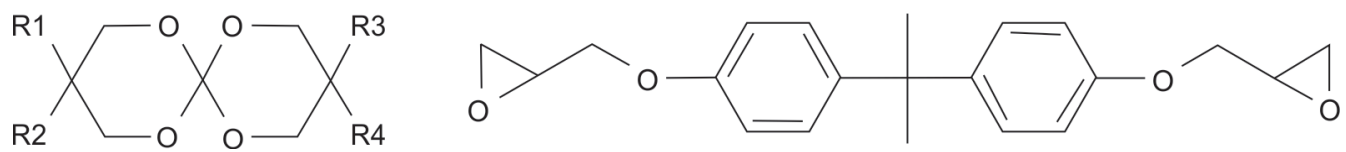

Fig. 5: Spiro-orthocarbonate (Source: From Weinmann W, Thalacker C, Guggenberger R. Siloranes in dental composites. Dent Mater 2005;21(1):68-74. DOI: $10.1016 /$ j.dental.2004.10.007.)

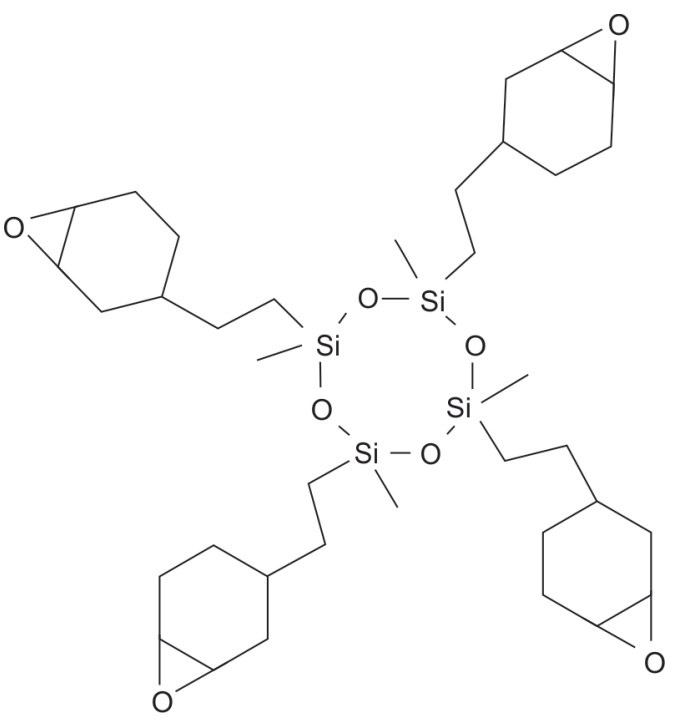

Fig. 6: Silorane (Source: From Weinmann W, Thalacker C, Guggenberger R. Siloranes in dental composites. Dent Mater 2005;21(1):68-74. DOI: 10.1016/j.dental.2004.10.007.)

B) Other compositional modifications

1) Modification of coupling agents

2) Modifying dimethacrylate formulations

3) Alternative photoinitiaters

4) Alternative coinitiators/accelerators

5) Bulk-fill concept

6) Ormocers

(III) Alternative curing protocols

A) Irradiance control

B) Placement techniques

C) Curing methods.

This review will focus on the first two methods of reducing polymerization shrinkage which are dependent on the composition.

Patel et al. found that on average, $22.5 \mathrm{~cm}^{3}$ volumetric reduction occurred per double bond in esteric methacrylates upon polymerization. ${ }^{2}$ Hence, molar volume increase is an attractive option to negate shrinkage.
While many strategies are explored to reduce or compensate for polymerization shrinkage in composites, the first two strategies prove to address the primary problem, while the third is designed to counter the effects of the same, namely polymerization shrinkage stress. The different compositional modifications can be subclassified as those pertaining to matrixes, fillers, coupling agents, initiators, and others (Fig. 7). Modifications in resin chemistry also include isobornyl acrylates. ${ }^{3}$ Factors other than chemistries affecting shrinkage behavior are the rate and extent of polymerization, degree of conversion or DC, and modulus of elasticity of the polymerized matrices. ${ }^{1,4}$ These factors help in reducing the shrinkage stresses. ${ }^{5}$

\section{Etiology and Effects}

During the polymerization of vinyl polymers, two processes happen to increase shrinkage, namely increase in density and decrease in mobility. In the last five decades, monomers and fillers have been extensively researched and modified to negate polymerization 


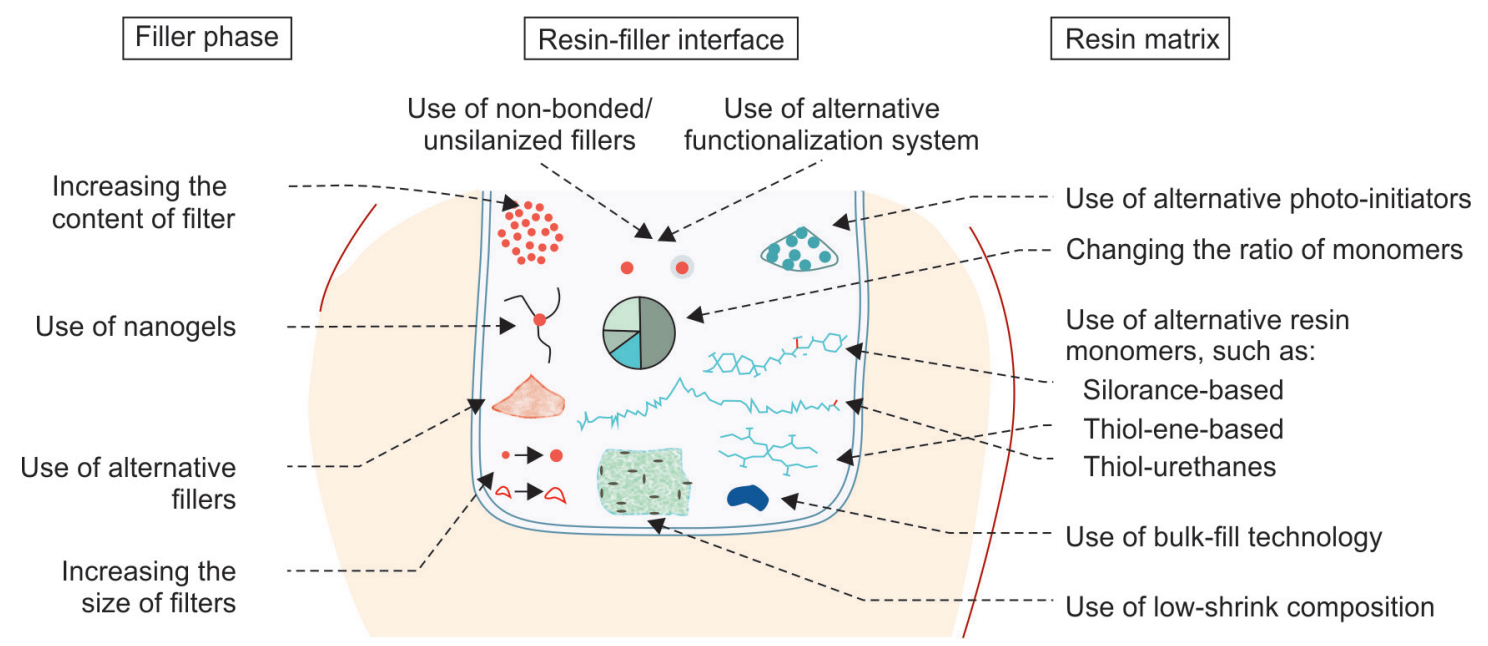

Fig. 7: Factors that can reduce polymerization shrinkage and/or shrinkage stress (Source: From Meereis CTW, Münchow EA, Oliveira da Rosa WL, et al. Polymerization shrinkage stress of resin-based dental materials: a systematic review and metaanalyses of composition strategies. J Mech Behav Biomed Mater 2018;82:268-281. DOI: 10.1016/j.jmbbm.2018.03.019.)

shrinkage. However, clinically lower shrinkage values do not always translate as less interfacial gaps or beneficial. In studies, it has been shown that low-shrinking monomers show less stress with low $\mathrm{C}$ factor while demonstrating more stress with high $\mathrm{C}$ factor. Calheiros et al. demonstrated that commercial low-shrink materials Aelite and In Ten S have greater stress and microleakage than regular hybrids. ${ }^{6,7}$ This is due to the fact that shrinkage is but only one factor among the multitude of factors responsible for shrinkage stress that is clinically more relevant, others being vitrification, elastic modulus, reaction rate, C-factor, and compliance of bonded surfaces. Compliance is a clinical phenomenon, which is affected by cavity geometry and stiffness of the remaining tooth structure. ${ }^{8}$ The time-dependent viscous flow of composites affects their plastic deformation that in turn impacts shrinkage stress relief. During the initial stages of polymerization, cyclization and chain growth are prioritized over cross-linking. Hence, interchain covalent bonds do not form and plastic deformation is ensured. It is the "rigid contraction" or postgel shrinkage that produces stress. Molecular resistance to flow is indicated by viscosity while monomeric flexibility is indicated by glass transition temperature $\left(T_{\mathrm{g}}\right)$. Together, they govern the molecular mobility of resins. ${ }^{7}$

\section{Methods of Reducing Polymerization Shrinkage and Shrinkage Stress}

\section{Reducing Reactive Sites}

Increasing Molecular Weight/Unit Volume of Resin/Reducing Double-bond Concentration of Resins

One of the popular methods of reducing shrinkage includes altering reactive group concentration. 9,10

Reactive group concentration can be reduced by using monomers with less double-bond concentration, thus decreasing polymerization shrinkage. Silsesquioxanes are popular in this category, especially the polyhedral oligomeric silsesquioxane (POSS). It has been proven to increase molecular weight and decrease double-bond concentration. Bisphenol A ethoxy fluorene methacrylate (BisEFMA) (Fig. 8) with higher molecular weight than conventional dimethacrylates was found to have the lowest shrinkage in a study. ${ }^{11}$ Multifunctionality decreases shrinkage

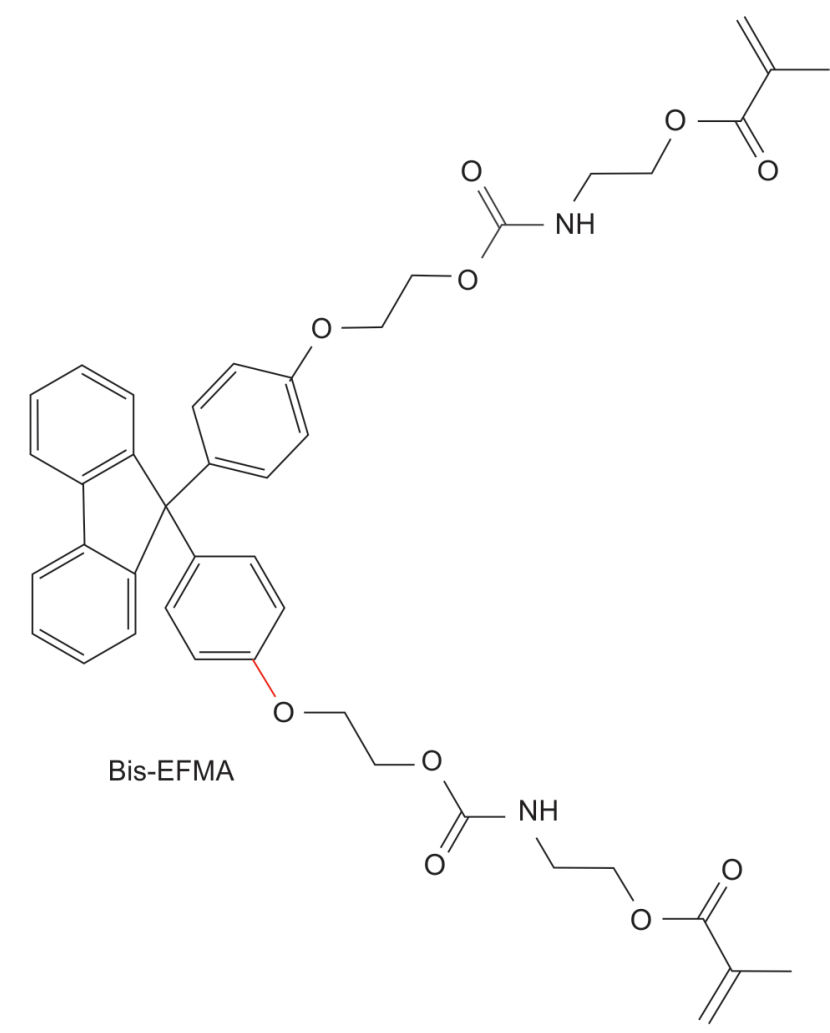

Fig. 8: Bisphenol A ethoxy fluorene methacrylate (Source: From He J, Kopperud HM. Preparation and characterization of BisGMA-free dental composites with dimethacrylate monomer derived from 9,9-Bis [4-(2-hydroxyethoxy)phenyl]fluorene. Dent Mater 2018;34(7):1003. DOI: 10.1016/j.dental.2018.03.007.)

without compromising mechanical properties. Introducing bulky substituent groups can increase molecular weight, molar volume, and decrease reactive double bonds. Mono-tertiary butyl and di-tertiary butyl groups can be added to methacrylate (Fig. 9) by ring-opening polymerization of the diepoxide with the corresponding phenol and reacting with methacrylic anhydride. ${ }^{12}$ DX-511 is a modified 


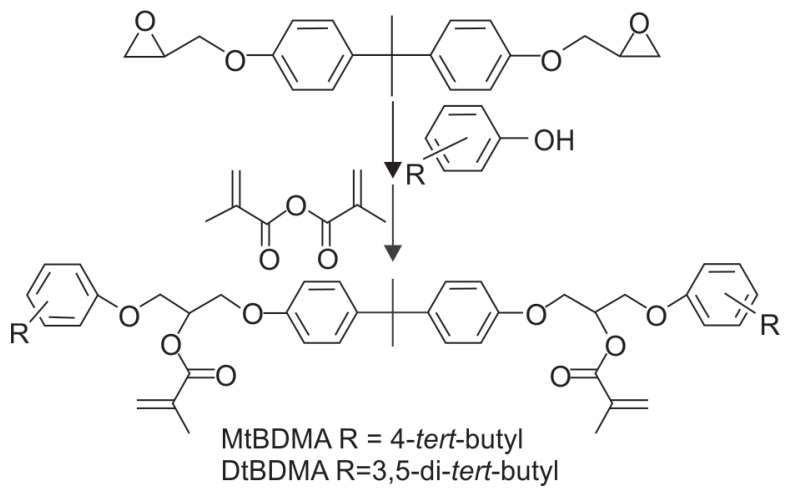

Fig. 9: Mono-tertiary butyl dimethacrylate (above); di-tertiary butyl dimethacrylate (below) (Source: From Ge J, Trujillo M, Stanbury J. Synthesis and photopolymerization of low shrinkage methacrylate monomers containing bulky substituent groups. Dent Mater 2005;21(12):1163-1169. DOI: 10.1016/j.dental.2005.02.002.)

Cationic cure

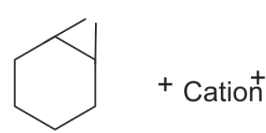

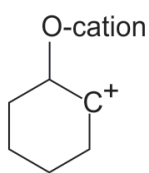
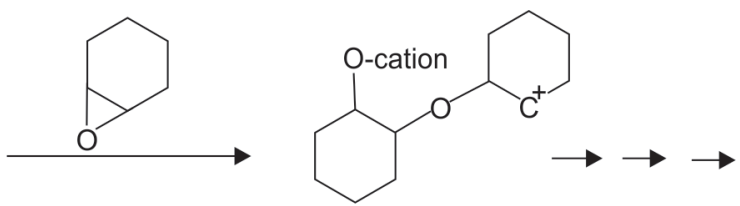

Fig. 10: Cationic ring-opening polymerization (Source: From Weinmann W, Thalacker C, Guggenberger R. Siloranes in dental composites. Dent Mater 2005;21(1):68-74. DOI: 10.1016/j.dental.2004.10.007.)

urethane dimethacrylate (UDMA), with high molecular weight and low double-bond concentration that leads to less shrinkage and shrinkage stress. It is commercially marketed as Kalore. ${ }^{8}$

\section{Increasing Filler}

Though resin matrix is primarily responsible for shrinkage, fillers also play a role. Though conventional wisdom has shown that filler loading reduces polymerization shrinkage, the higher it is, the greater is the light scattering, which hinders photopolymerization, and the greater is the viscosity, and few studies indicate that lower filler volume gives rise to low shrinkage and shrinkage stress. Both filler content and size play a major role in affecting shrinkage and shrinkage stress. It was found that even a $5 \%$ increase in filler content significantly reduced shrinkage stress. Also, a positive correlation between filler size and stress reduction was especially noticed for spherical fillers. This is due to more translational and rotational movement within the resin matrix. However, since contemporary dental composites rely more on nanofillers for optical properties and aesthetics, this above-mentioned phenomenon is immaterial. ${ }^{8}$ In addition to the polymerization shrinkage and shrinkage stress, thermal expansion mismatch and modulus mismatch between fillers and resins result in additional stresses. $4,13,14$

High inorganic filler content increases stiffness and also shrinkage stress. High-density polyethylene (HDPE) spheres are substituted in part for stiff fillers to counteract this. A $20 \%$ of addition resulted in $25 \%$ of reduction of stress. However, crucial mechanical properties may be compromised in such materials. ${ }^{1}$ Cross-linked polymeric nanoparticles have been shown to reduce shrinkage by $7-30 \%$, stress from $2-18 \%$ when added in the range of $5-25 \%$. E-glass fibers that have similar modulus and stiffness of particulate glass fillers were found to relieve stress by $5 \%$ due to increased compliance. ${ }^{8}$

Nanogels are single- or multichain polymeric particles that are cyclized and cross-linked internally, which allows cross-linking of the resin matrix by physical entanglement or chemical means. Further, they delay modulus development and vitrification. ${ }^{8}$ Reactive nanogel prepolymer additives achieved less stress without light attenuation. Reactive organic nanogel prepolymers slow down reaction rate to reduce shrinkage. In a systematic review, the authors studied the role of fillers and other components on polymerization shrinkage and shrinkage stress reduction; 62 laboratory studies were qualitatively synthesized, and 58 quantitatively. They found that the fillers had a range of $2-59 \%$ in reducing the stress, and nanogel incorporation was found to be the best method among the fillers' modifications. ${ }^{8}$

\section{Introducing New Chemistries}

\section{Alternative Polymerization}

Ring-opening polymerization: Ring-opening polymerization ${ }^{15}$ has the unique advantage of volumetric gain due to the reverse situation, of a closed ring in a monomer occupying less space than the open ring in a polymer, as against the linear molecule of conventional resins.

Liquid crystalline monomers undergo a transition of their nematic phase to an isotropic amorphous state resulting in reduced shrinkage. Vinyl cyclopropanes undergo ring-opening polymerization via radicals. They can be copolymerized with methacrylates. Free-radical ring-opening polymerization of spiro-orthoesters, carbonates, and cyclic acrylates increases their molar volume. ${ }^{16}$ Spiro-orthocarbonates ${ }^{17}$ undergo ring-opening polymerization via cation (Fig. 10). Their expansion potential was first elucidated by Bailey in 1975. Thompson investigated their use in dentistry in 1979. On average, they show $3-4 \%$ of expansion particularly with the tetraoxaspiro-undecane (TOSU) type of spiro-orthocarbonates, based on if the cis or trans isomer (Fig. 11) is used..$^{18}$ They have the ability to reduce shrinkage stress from $48-99 \%$. They reduce modulus during polymerization, glass transition temperature, reaction rate and hence increase 


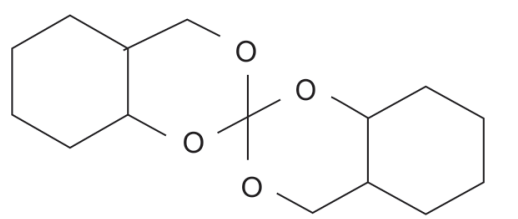

$\mathrm{CIS} / \mathrm{CIS} \mathrm{SOC}$

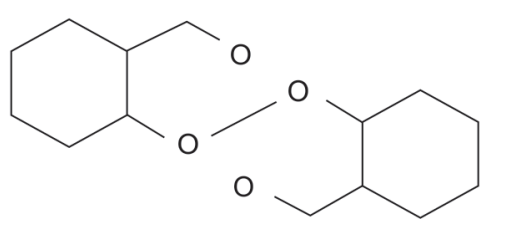

CIS/TRANS SOC

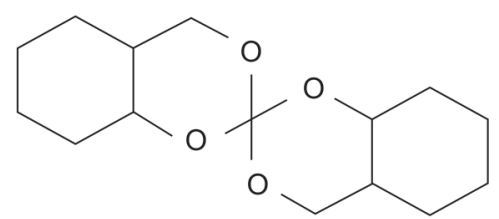

TRANS/TRANS SOC

Fig. 11: 2,3,8,9-Ditetramethylene-1,5,7,11 tetraoxaspiro-5.5 undecane (TOSU) and its isomers (Source: From Byerley TJ, Eick JD, Chen GP, et al. Synthesis and polymerization of new expanding dental monomers. Dent Mater 1992;8(6):345-350. DOI: 10.1016/0109-5641(92)90016-6.)
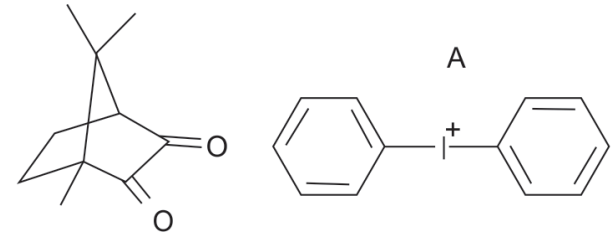

Electron donor

Fig. 12: Cationic photoinitiators (Source: From Weinmann W, Thalacker C, Guggenberger R. Siloranes in dental composites. Dent Mater 2005;21(1):68-74. DOI: 10.1016/j.dental.2004.10.007.)

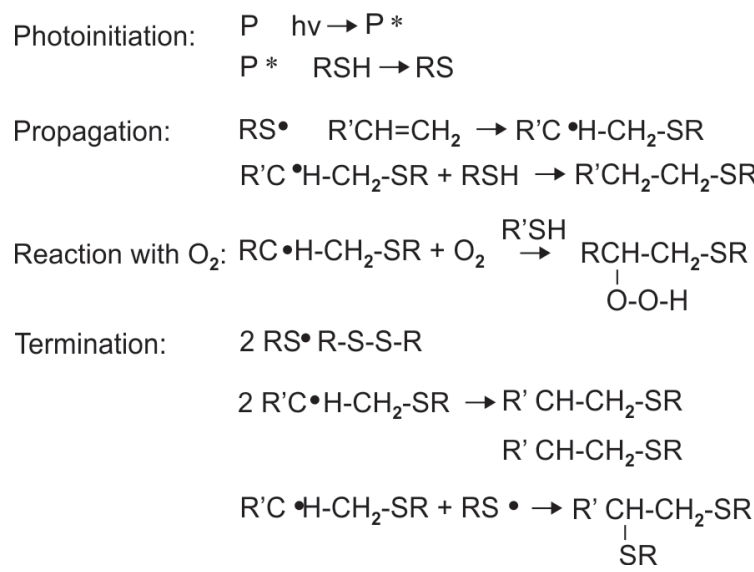

Fig. 13: Step-growth polymerization (Source: From Lu H, Carioscia JA, Stansbury JW, et al. Investigations of step-growth thiolene polymerizations for novel dental restoratives. Dent Mater 2005;21(12):1129-1136. DOI: 10.1016/j.dental.2005.04.001.)

gel point. ${ }^{8}$ They can be copolymerized with epoxy monomers. Cyclopolymerization of multifunctional oligomers has been found to reduce shrinkage. ${ }^{19}$ Siloranes are hybrid monomers with siloxane backbone for hydrophobicity and oxirane for reducing shrinkage. The ring-opening polymerization occurs by an acidic cationic initiator. The opened ring becomes a new carbocation to propagate the reaction. Cationic ring-opening polymerization generally utilizes three-component initiator system of iodonium salt as acid generator, camphorquinone (CQ) as photosensitizer, and an electron donor as redox (Fig. 12). Counteranions in acid generator iodonium salt like antimonate increase the reactivity. Siloranes were found to have less than $1 \%$ of final shrinkage that is probably one of the lowest known for hithertofore..$^{17}$ They have been found to reduce stress by $97 \%$ in many studies and were found to increase flow in the pre-gelation phase; nonetheless, some studies found them to be not beneficial in reducing stress. ${ }^{8}$ Siloranes are available commercially as Filtek P90, Filtek Silorane P90, and FiltekLSLow Shrink. In a recent systematic review cum meta-analyses, Magno and others reviewed 11 clinical studies comparing silorane to methacrylates and concluded that they performed clinically equal without any significant difference. ${ }^{20}$

Step-growth Polymerization: Another method of decreasing shrinkage is by delaying gel point. This is achieved through thiolMichael step-growth polymerization (Fig. 13). ${ }^{21}$ Yet another category of materials with delayed gelation are thio-urethanes. Oligomers with pendant thiol groups undergo chain transfer with methacrylate to delay vitrification. This relieves stresses. ${ }^{22}$ One such material was synthesized from 4,4-methylene bis(cyclohexyl isocyanate), trimethylol-tris-3-mercaptopropionate, and 3-(triethoxysilyl) propyl isocyanate with triethylamine as catalyst. ${ }^{23}$ Thio-urethanes have greater toughness and chemical stability and also have a potential to reduce shrinkage stress from 10-88\%. Among the step-growth polymers, they were found to be the best in reducing shrinkage stress in a systematic review cum meta-analyses. ${ }^{8}$ Posner was the first person to discover the thiol-ene polymerization. The advantages include nearly complete consumption of all reactive groups, improved depth of cure and flexibility. Thiol-ene ${ }^{9}$ polymerization has shown a significant reduction in shrinkage stress in many studies. The thiol (Fig. 14) pentaerythritol mercaptopropionate (PETMP) and the ene, a triallyl ether, triallyl triazine trione (TATATO) combination (Fig. 15) showed $86 \%$ of reduction in stress. ${ }^{24}$ In stepgrowth polymerization, the scope for stress relief is more. Here, a thiyl radical gets added to an ene molecule and a chain transfer occurs to a thiol group freeing the thiyl radical again (Fig. 13). Apart from the rapid rate, they are also insensitive to $\mathrm{O}_{2}$ inhibition. Upon combining with methacrylates, there is homopolymerization of methacrylates initially, followed by thiol-ene step-growth later. However, if thiol ratio is less, conversion will be low. To offset this, more thiol:ene has to be added. This has a downside of producing a bad odor. This problem can, however, be controlled to some extent by using high molecular weight thiols like tetrafunctional thiol monomer. Upon further mixing with methacrylates and fillers, the odor disappears. The advantage of any thiol is that they act as diluent throughout the reaction. Popular thiol PETMP and ene, a triallyl like the TATATO or trinorbornene, trimethylolpropanetrinorbornene carboxylate (TMPNC) can be effectively used with methacrylates in dental composites (Fig. 16). With ethoxylated Bisphenol A dimethacrylate (EBPADMA) (Fig. 17) if added in the ratio of 2:1 thiol-ene (PETMP:TMPNC), they shrank the least. Seventy-four percent of the reduction of shrinkage stress was seen compared to EBPADMA:TEGMA composite with adequate mechanical properties. However, when triallyl ether ene, TATATO, was used, $50 \%$ of reduction in shrinkage stress without much compromise on mechanical properties was achieved. ${ }^{14}$ Thiol-ene polymerization can reduce stress from 35-94\%, especially upon combining with methacrylates or oligomers. Though they were comparatively inferior to siloranes in reducing the polymerization shrinkage stress, they have moderate 


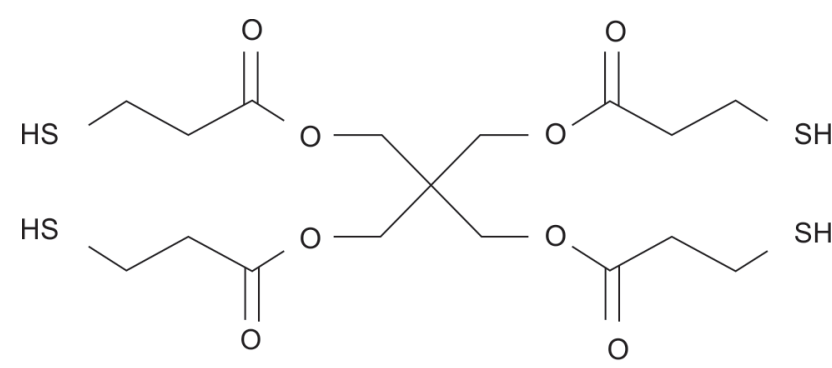

Pentaerythritol tetra (3-mercaptopropionate) (PETMP)

Fig. 14: Commonly used thiol in step-growth polymerization pentaerythritol tetramercaptopropionate (PETMP) (Source: From Cramer NB, Stanbury JW, Bowman CN. Recent advances and developments in composite dental restorative materials. J Dent Res 2011;90(4):402-416. DOI: $10.1177 / 0022034510381263$.

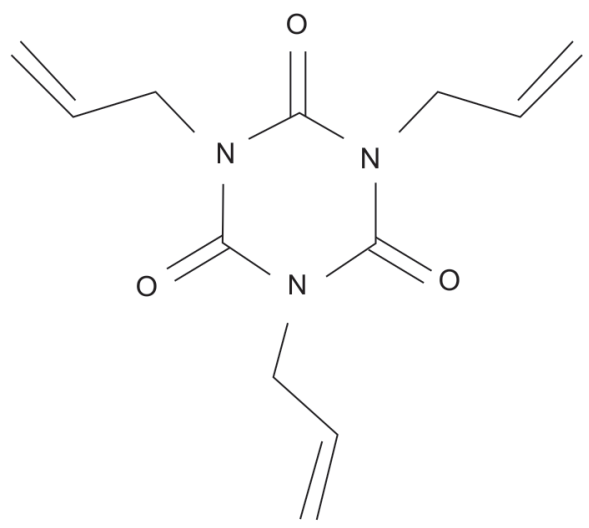

Triallyl triazine trione (TATATO)

Fig. 15: Commonly used triallyl ether "ene" in thiol-ene polymerization triallyl triazine trione (TATATO) (Source: From Cramer NB, Stanbury JW, Bowman CN. Recent advances and developments in composite dental restorative materials. J Dent Res 2011;90(4):402-416. DOI: 10.1177/0022034510381263.)

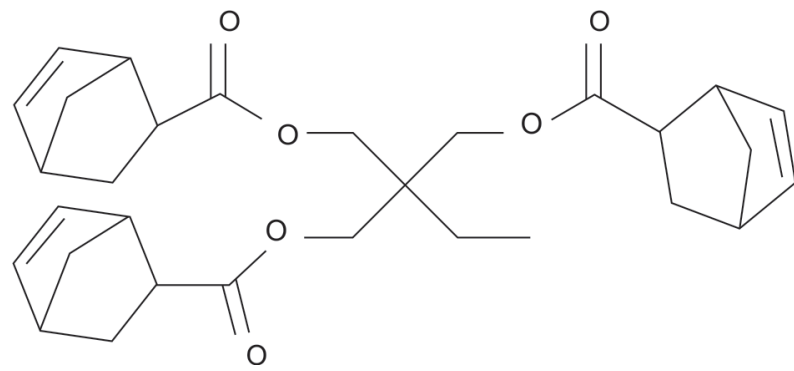

Fig. 16: Commonly used norbornene "ene" in thiol-ene polymerization trimethylolpropanetrinorbornene carboxylate (Source: From Cramer NB, Stanbury JW, Bowman CN. Recent advances and developments in composite dental restorative materials. J Dent Res 2011;90(4):402-416. DOI: $10.1177 / 0022034510381263$.

potential in doing so, according to a recent systematic review cum meta-analyses of in vitro studies. ${ }^{8}$

In resins, nonreactive prepolymers and marginally compatible comonomers relieve stress (Fig. 18) by polymerization-induced phase separation ${ }^{14}$ (PIPS). Hydrogenated dimer acids have high molecular weight and hence low shrinkage. Dimer acid derivate,

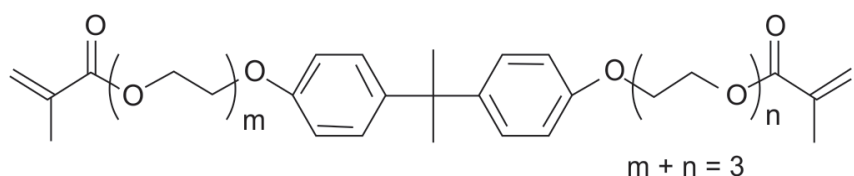

Fig. 17: Ethoxylated Bisphenol A dimethacrylate (EBPADMA) (Source: From Cramer NB, Stanbury JW, Bowman CN. Recent advances and developments in composite dental restorative materials. J Dent Res 2011;90(4):402-416. DOI: 10.1177/0022034510381263.)

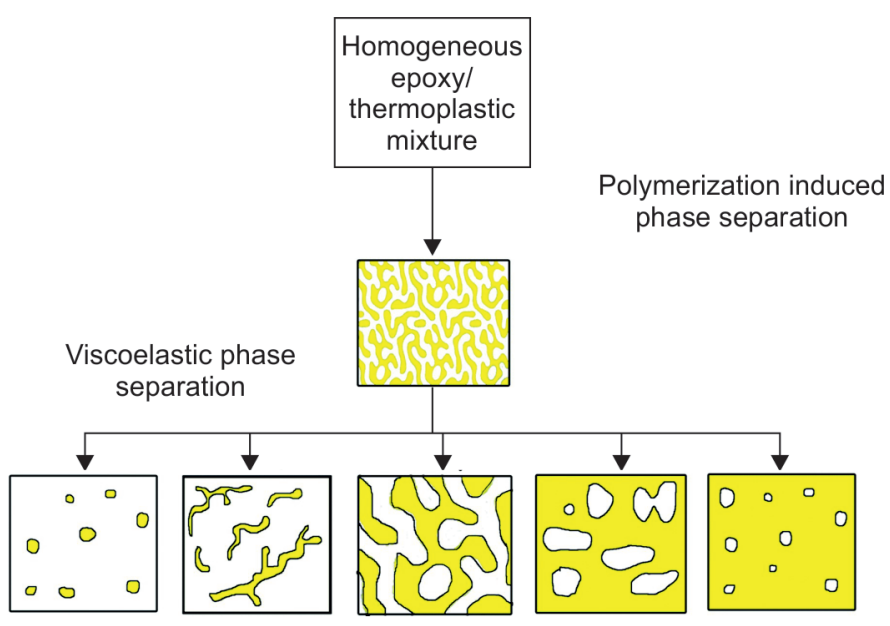

Fig. 18: Polymerization-induced phase separation (PIPS) (Source: From pubs.rsc.org.)

dimer dicarbamate dimethacrylate is a low-shrinking high molecular weight monomer that uses PIPS to reduce shrinkage and shrinkage stress. Commercially, it is available as N'Durance. ${ }^{8}$

\section{Other Compositional Modifications \\ Modification of Coupling Agents}

Nonfunctional silane-treated fillers produced less stress without compromising conversion unlike functional fillers. Oligomerization involves prereacting functionalities to reduce reactive species concentration. Alternative functionalization of fillers had a greater ability to reduce shrinkage stress than nonbonded, nonsilanized, and silane-treated fillers. Nonbonding and nonsilanization also improved rotational and translational movement of fillers to reduce stress. But mechanical properties could be compromised by this method. Nonfunctional fillers decrease chemical interaction with resin, to improve compliance. Further, the nonfunctional silane favored pregelation contraction. These filler types do not affect mechanical properties. Among functionalized fillers, flexible hyperbranched oligomer functionalized fillers and thiol functionalized fillers substantially reduce stress. This is due to the enhanced mobility of molecules. They also lower the modulus. Overall, any modification of coupling agent was able to reduce stress from 8-46\% much lower than filler and very much lower than the resin matrix modifications. ${ }^{8}$

Dynamic bond exchange of DCC facilitates relieving stresses from polymerization reaction and external loading while preserving overall covalent bonded structure in polymeric backbone. This is possible through reversible addition fragmentation chain transfer (RAFCT). However, it can negatively impact Young's modulus, glass transition, and fracture toughness. Precisely targeting the filler 


\section{A. Dynamic Covalent Chemistries (DCCs)}

Thiol-Thioester Exchange (TTE)

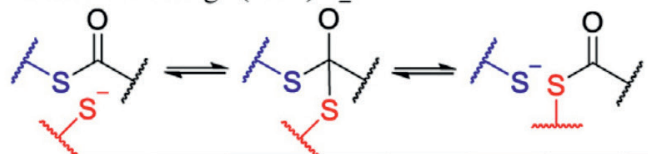

\section{B. Bulk DCC and Interfacial DCC}

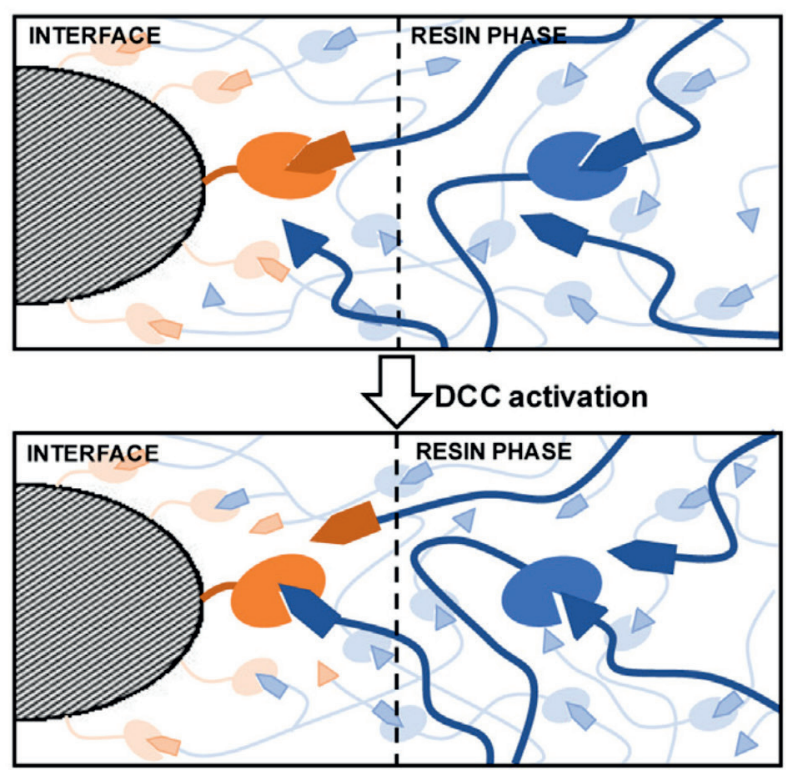

Reversible Addition-Fragmentation Chain Transfer (RAFT)

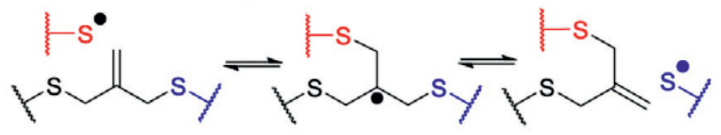

\section{Material Formulations}<smiles>C=C(C)C(=O)OCCCOCCOCCOC(=O)C(=C)C</smiles><smiles></smiles>
TTE-SNP<smiles></smiles>

C-SNP<smiles>C1CN2CCN1CC2</smiles>

$\mathrm{DABCO}$

Figs 19A to C: Dynamic covalent chemistry and reversible addition fragmentation chain transfer (Source: From Sowan N, Dobson A, Podgorski M, et al. Dynamic covalent chemistry (DCC) in dental restorative materials: implementation of a DCC-based adaptive interface (Al) at the resin-filler interface for improved performance. Dent Mater 2020;36(1):53-59. DOI: 10.1016/j.dental.2019.11.021.)<smiles>C=COCCSCC(=C)CSCCOC=C</smiles>

MDTVE/AFT<smiles>C=COCCOCC(C)C(F)(F)F</smiles>

TEGDVE/non AFT 3

Fig. 20: Methylenepropane dithioethyl vinyl ether (left) based on addition fragmentation chain transfer (AFCT); triethylene glycol divinyl ether (right) not based on AFCT (Source: From Sowan N, Dobson A, Podgorski M, et al. Dynamic covalent chemistry (DCC) in dental restorative materials: implementation of a DCC-based adaptive interface (AI) at the resin-filler interface for improved performance. Dent Mater 2020;36(1):53-59. DOI: 10.1016/j.dental.2019.11.021.)

particle-resin interface with this DCC could be more beneficial without impacting the mechanical properties. RAFCT-adaptive interface can relieve stress even in inert thiol-ene composite. A modification of this is thiol-thioester DCC moieties (Fig. 19) in conventional resin composite that is active even after light withdrawal as it is based on base-nucleophile catalyst. Further, a thiyl radical is not required for bond exchange and hence is compatible with multimethacrylate composites. This is carried out by functionalizing silica nanoparticles with TTE silane and along with a nuclephile, introduction into a BisGMA-triethylene glycol dimethacrylate (TEGDMA) composite. A continuous bond cleavage happens with reversible reformation that relieves polymerization shrinkage stresses. Two DCC approaches are there, one in resin using RAFCT and the other at the interface using TTE; they act synergistically to improve mechanical properties and relieve stresses. In composites, bulk shrinkage stresses are responsible for failures by causing microcracks and debonding. Thus, composites with only filler-resin interface modification were found to have
$30 \%$ of lower polymerization shrinkage stresses, double that Young's modulus, $30 \%$ of more flexural strength, and $25 \%$ of more flexural toughness compared to conventional composites. These composites contain a divinyl addition fragmentation chain transfer (AFCT) [2-methylenepropane-1,3-di(thioethyl vinyl ether) (MDTVE)] or non-AFCT [triethyleneglycol-divinylether (TEGDVE)] (Fig. 20) and PETMP, with TTE-based fillers in the presence of nucleophile catalyst 1,4 diazabicyclo 2,2,2 octane (DABCO). If both resins and fillers are modified, $90 \%$ of reduction in stress is observed. ${ }^{25}$

\section{Modifying Dimethacrylates}

Modifying dimethacrylate formulations ${ }^{26,27}$ is an equally promising area of research in reducing polymerization shrinkage and shrinkage stress.

Ethoxylated methacrylates and hyperbranched methacrylates have high molecular weight and hence demonstrate low shrinkage. Trifunctional monomers, like triphenylolmethane triglycidyl ether methacrylate (TTEMA) (Fig. 21) shrank less at only $2 \%$ compared 


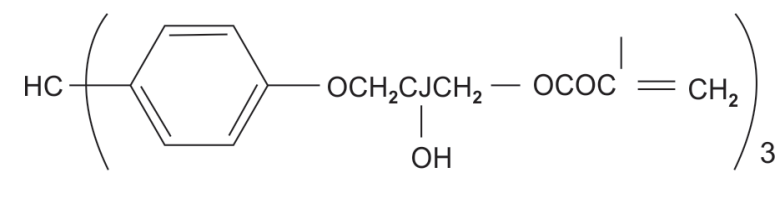

TTEMA

Fig. 21:Tris triphenylolmethane triglycidyl ether methacrylate (TTEMA) (Source: From Chung CM, Kim JG, Kim MS, et al. Development of a new photocurable composite resin with reduced curing shrinkage. Dent Mater 2002;18(2):174-178. DOI: 10.1016/s0109-5641(01)00039-2.)

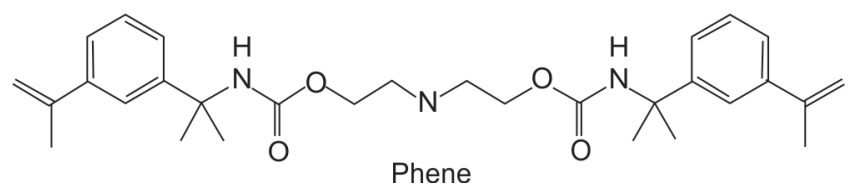

Fig. 22: N-methyl bis ethyl-carbamate-isopropyl-methylstyryl amine (phene) (Source: From He J, Garoushi S, Säilynoja E, et al. The effect of adding a new monomer "Phene" on the polymerization shrinkage reduction of a dental resin composite. Dent Mater 2019;35(4):627-635. DOI: 10.1016/j.dental.2019.02.006.)

to BisGMA, TEGDMA, and UDMA which shrank by 5,14 , and $9 \%$, respectively. When combining with TEGDMA at 3:2 ratio, a $10 \%$ of reduction was noted. ${ }^{27}$

Chain transfer agents increase mobility to achieve low shrinkage. Allyl sulfides and trithiocarbonates cause bond rearrangement to reduce shrinkage. ${ }^{28}$ Functionalities that are capable of AFCT reaction like trithiocarbonates facilitate network rearrangement like thiol-enes and thio-urethanes. This leads to $25-54 \%$ of shrinkage stress reduction if they are added to dimethacrylates in the proportion of $1.5-2 \%$. However, upon increasing their quantity to $30 \%, 65 \%$ of reduction in shrinkage stress can be achieved. While allyl sulfides in norbornene-methacrylate monomers can reduce shrinkage stress from 35 to $95 \%{ }^{8}$

Methylstyryl groups have been reported to have lower reactivity than methacrylate groups ${ }^{29}$ which causes delayed gelation resulting in stress relief. "phene" [N-methyl-bis(ethylcarbamate-isopropyl-methylstyryl)amine ${ }^{30}$ is an innovative monomer with high molecular weight. Further, it has lower double-bond concentration; the three properties together cause lower shrinkage, slow reactivity, and lower shrinkage stress. Phene (Fig. 22) is synthesized from N-methyl diethanol amine (MDEA) and 3-isopropenyl dimethylbenzyl isocyanate (IDI). Even at room temperature, methylstyrene groups have appreciable depropagation. This causes slow polymerization rate and crosslinking density. Hence, Phene-containing composites have delayed vitrification and low polymerization shrinkage stresses. This is attributed to delocalization of double bonds owing to phene's resonance structure. This inhibits the free-radical addition reaction and results in lower reactivity. In a study, up to $40 \%$ of Phene was added to conventional matrix and tested. It was found that the higher the Phene, the lower the shrinkage, shrinkage stress, flexural strength, flexural modulus, DC, and greater the wear and fracture toughness. $^{31}$

The lower molecular weight diluents have dense double bonds that increase shrinkage. They tend to increase mobility and decrease $T_{\mathrm{g}}$. By just decreasing TEGDMA by half, shrinkage stress was found to decrease by $15-46 \%{ }^{8}$ Nevertheless, the stress values of low- viscosity low-stiff materials are equivalent to high-viscosity highstiff materials. If polyethylene glycol (PEG) substitutes triethylene glycol (TEG), in the spacer, shrinkage can be reduced; however at the same time, $T_{\mathrm{g}}$ and mechanical properties will be decreased. Acetyloxypropylene dimethacrylate as a substitute for TEGDMA has been found to shrink less, however has less DC also. This is because the chain separating the unsaturation is comparatively shorter. ${ }^{32} \mathrm{Bis}$ acryloxymethyltricyclodecane (TCD-DI-HEA) has low viscosity and produced less shrinkage stress and hence can replace TEGDMA. As it has three aromatic rings in the backbone of the polymer, it has greater flexibility and can accommodate shrinkage better. Moreover, it has lower modulus and low-cross-linking potential which also aid in relieving stress. Commercially it is marketed as Venus Diamond. ${ }^{8}$

The overriding factor on molecular mobility is the structure and functionalities of the monomers. For example, UDMA has two urethane groups with labile $\mathrm{H}$ atoms of $\mathrm{NH}$ groups. They favor chain transfer reactions like $\sim \mathrm{M} \bullet+\mathrm{NH} \rightarrow \sim \mathrm{MH}+\mathrm{N} \bullet$ where $\mathrm{M} \cdot$ is a macroradical, while the $\mathrm{NH}$ group may be from monomer or polymer. So the $\mathrm{NH}$ is an active site and capable of reticulation which is the highest for UDMA among dimethacrylates. This results in a dense network. $\mathrm{N} \cdot$ radical participates in cross-linking and hence the greater shrinkage of UDMA than BisGMA. ${ }^{7}$ If UDMA substitutes TEGDMA, shrinkage decreases to a great extent. However, if relative ratio of UDMA:BisGMA was increased, shrinkage increases. $^{33}$

Urethane dimethacrylate derivates have been found to shrink less (Fig. 23). Low-shrinkage urethane dimethacrylate derived from isophorone (IP) diisocyanate, PEG in the presence of dibutylene dilaurate, and hydroxy ethyl methacrylate (HEMA) have been termed IP-UDMA (Fig. 24). They shrink less without compromising DC. ${ }^{34}$ Those derived from cycloaliphatic or aromatic diisocyanates (Fig. 23) shrank considerably less than fully aliphatic ones. Dimethacrylates with cyclohexyl methylenediisocyanate (CHMDI) or methylene diisocyanate (MDI) as core were found to shrink the least, nonetheless had lower hardness, $T_{\mathrm{g}}$ and modulus too. ${ }^{35}$

Organogelators, like dibenzylidinesorbitol (DBS) can induce physical gelation owing to their ability to form self-assembled networks. However, this reduces conversion. Less reactive solvents have been shown to reduce overall reaction kinetics and hence stress. ${ }^{8}$

Polymerization inhibitors, like butylated hydroxy toluenes can be increased to extend pre-gelation stage and thus decrease shrinkage stress. However, the downside of this strategy is the reduced degree of conversion. Thus, this may not be a viable solution for decreasing shrinkage stress. ${ }^{8}$

Certain commercial composites are formulated with less resin matrix volume to decrease shrinkage stress. One such material is Aelite LS, which has only $26 \%$ of resin matrix as opposed to $40 \%$ in other equivalent composites. ${ }^{8}$ Without any other modification, this method also proves to be useful in reducing both shrinkage and shrinkage stress.

\section{Alternative Photoinitiators}

A patent-registered UDMA molecule with an inbuilt photoactive molecule (photomodulator) is being marketed as stress-decreasing resin (SDR). This has been found to have the least stress among many low-shrinkage materials including silorane. Its rigidity was also comparatively more. ${ }^{36} \mathrm{~A}$ randomized clinical trial of this resin for 3 years showed 0 failures as opposed to $1.3 \%$ of annual failure rate (AFR) for nanohybrids in posterior restorations. However, the difference was not statistically significant. ${ }^{37}$ 


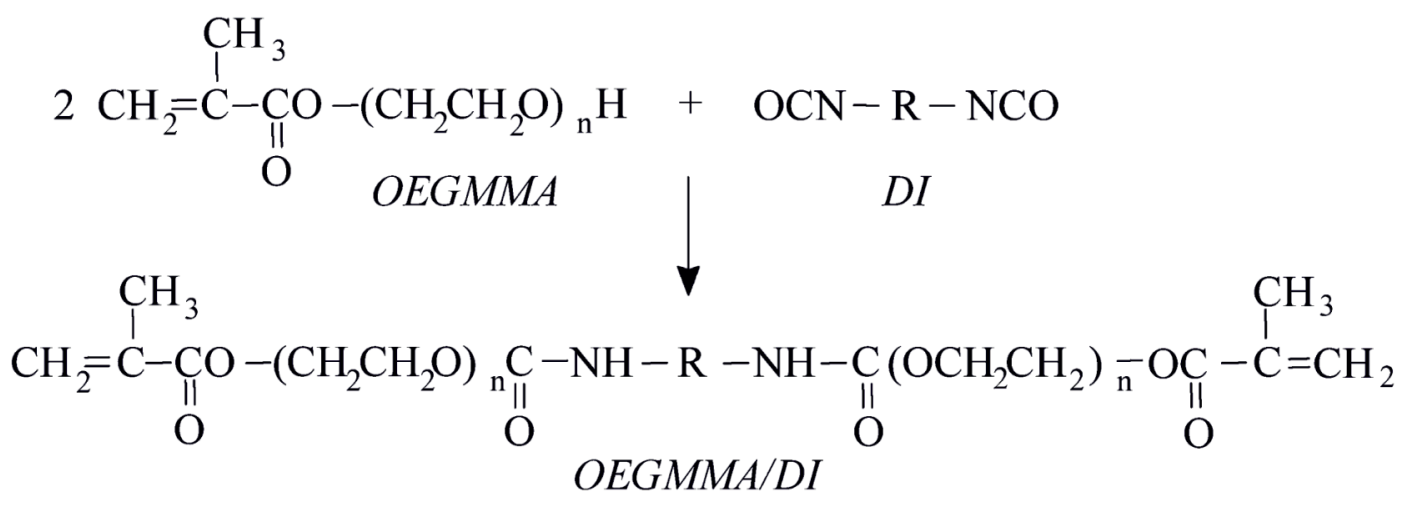

$$
\begin{aligned}
& \text { OEGMMA }(n=1-4): \\
& n=1 \text { HEMA } \quad n=2 \text { DEGMMA } n=3 \text { TEGMMA } n=4 \text { TTEGMMA }
\end{aligned}
$$

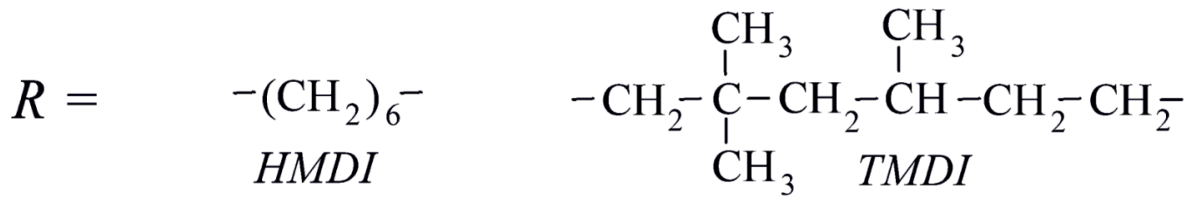

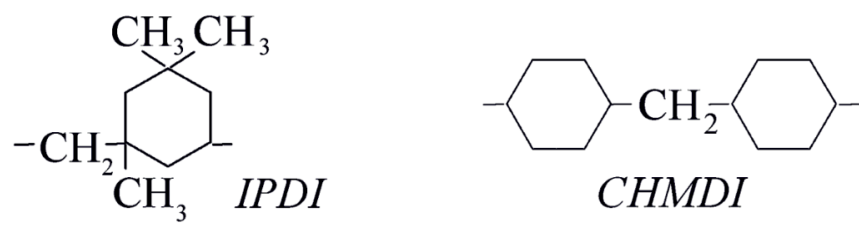

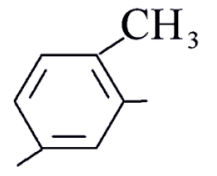

$T D I$

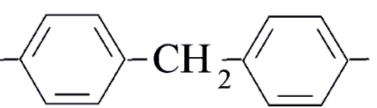

$M D I$

Fig. 23: UDMA derivatives containing different ethylene glycol methacrylate and diisocyanates (Source: From Barszczewska-Rybarek IM. Characterization of urethane-dimethacrylate derivatives as alternative monomers for the restorative composite matrix. Dent Mater 2014;30(12):1336-1344. DOI: 10.1016/j.dental.2014.09.008.)

Just by reducing the content of camphorquinone, shrinkage and shrinkage stress can be reduced to $12 \%$ but it could also decrease degree of conversion. ${ }^{8}$

Copper(I)-catalyzed azide-alkyne cycloadditions (CuAACs) ${ }^{13,38}$ have been shown to have significantly less shrinkage and shrinkage stress than conventional photoinitiated polymerization.

Photoinitiated photo-CuAAC has certain advantages over camphorquinone (Fig. 25):

- Cuhas longer lifetime and hencegreater degree of polymerization and dark reaction.

- Step-growth nature of this causes narrow $T_{\mathrm{g}}$ and homogeneous networks.
- Delaying gelation means low stresses.

- The triazole in polymer enhances mechanical properties.

This click chemistry was introduced in 2001 as a robust and orthogonal alternative to conventional polymerization. CuAAC is prepared by mixing stoichiometric ratios of diazide and trialkyne (Fig. 26) with 2 mol\% of $\mathrm{CuCl}_{2}, \mathrm{~N}, \mathrm{~N}, \mathrm{~N}, \mathrm{~N}, \mathrm{~N}$-pentamethyldiethylenetriamine (PMDETA), CQ, and 4-ethyl dimethyl aminobenzoate (EDMAB). Such resins showed three to four times lower shrinkage stress than conventional resins. The gel point was delayed till $80 \%$ of DC occurred, while it happened at $5 \%$ of DC for conventional resins. ${ }^{38}$

1-Phenyl 1,2-propanedione (PPD) has been shown to produce less shrinkage stress by lowering the rate of polymerization 


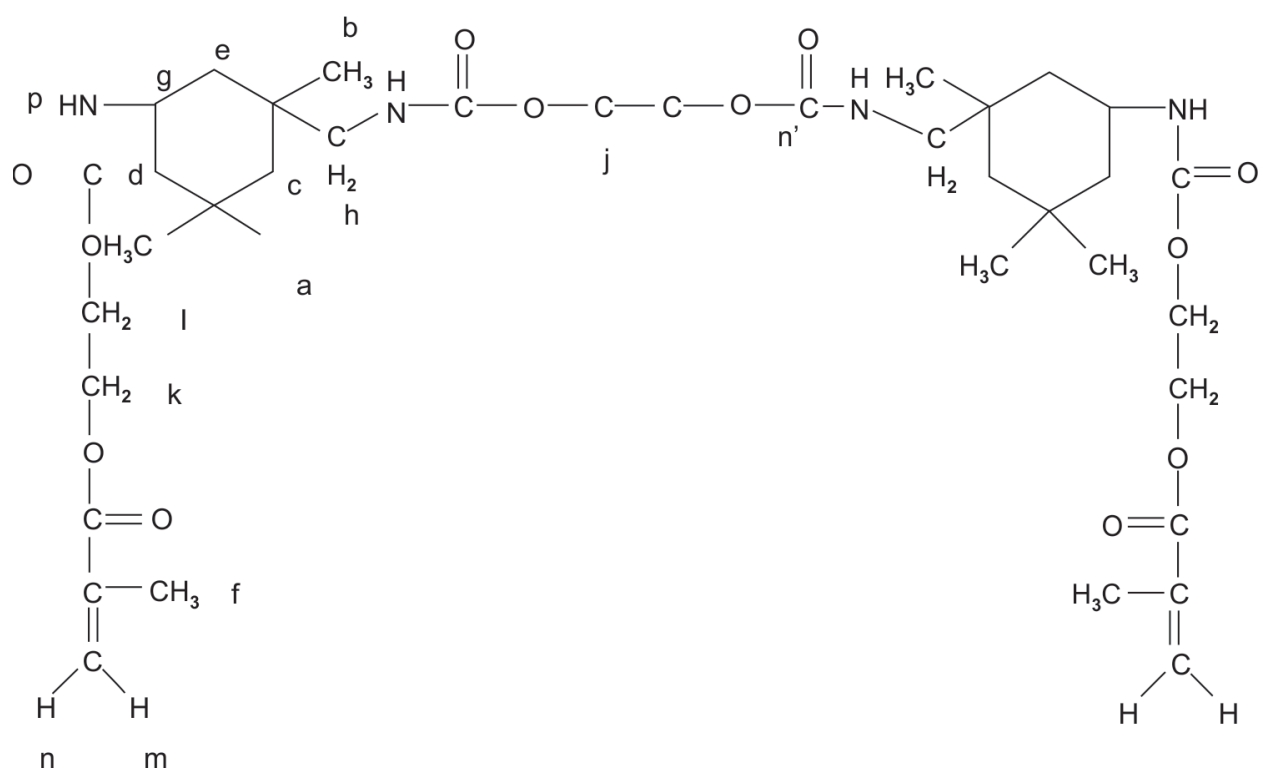

Fig. 24: Isophorone UDMA (IP-UDMA) (Source: From Atai M, Ahmadi M, Babanzadeh S, et al. Synthesis, characterization, shrinkage and curing kinetics of a new low-shrinkage urethane dimethacrylate monomer for dental applications. Dent Mater 2007;23(8):1030-1041. DOI: 10.1016/j. dental.2007.03.004.)

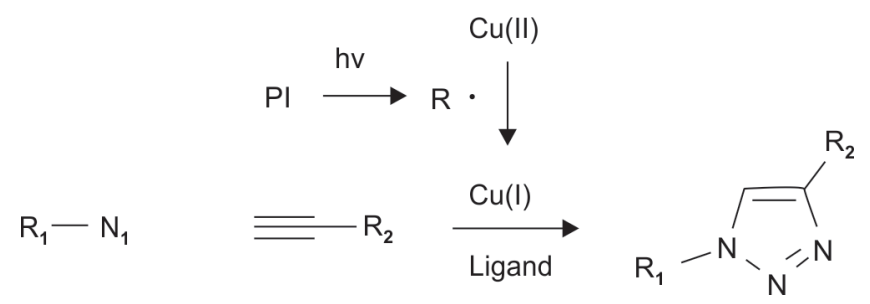

Fig. 25: Copper(I)-catalyzed azide-alkyne cycloaddition (CUAAC) reaction (Source: From Song HB, Sowan N, Shah PK, et al. Reduced shrinkage stress via photo-initiated copper(I)-catalyzed cycloaddition polymerizations of azide-alkyne resins. Dent Mater 2016;32(11):1332-1342. DOI: 10.1016/j.dental.2016.07.014.)

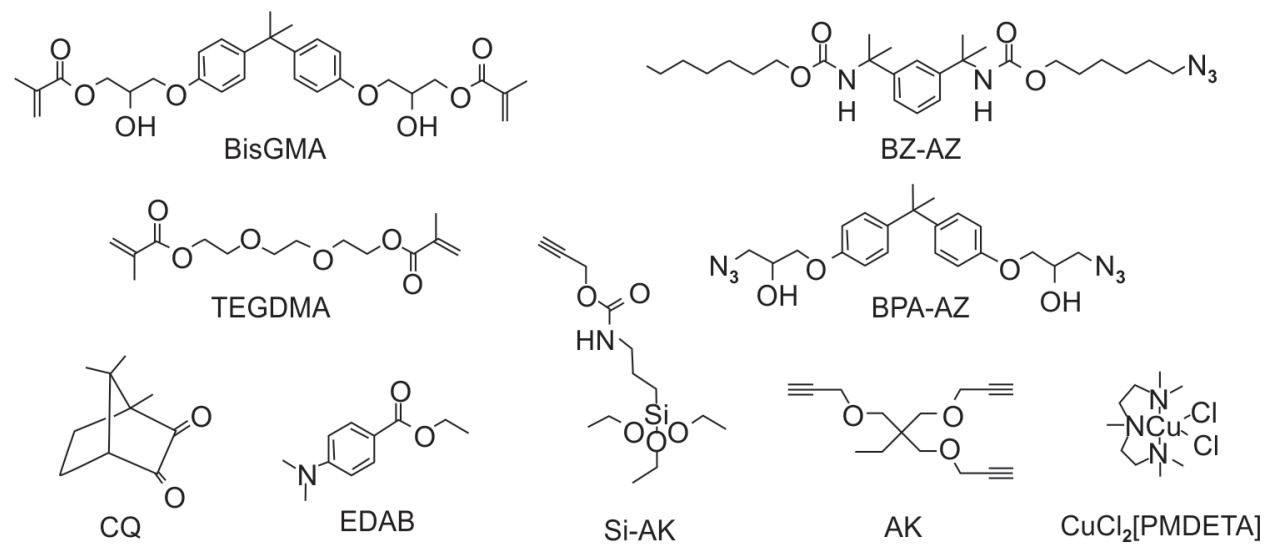

Fig. 26: Azide alkyne monomers, complimentarily functionalized Si fillers and catalysts for CuAAC (Source: From Song HB, Sowan N, Shah PK, et al. Reduced shrinkage stress via photo-initiated copper(l)-catalyzed cycloaddition polymerizations of azide-alkyne resins. Dent Mater 2016;32(11):1332-1342. DOI: 10.1016/j.dental.2016.07.014.)

reaction. ${ }^{8}$ Monoacylphosphene oxide (MAPO)-initiated composite exhibited low stresses (7 $\mathrm{MPa}$ ) comparable to $\mathrm{CQ}$ (5.5 $\mathrm{MPa}$ ) even at higher irradiance and very low stresses at normal irradiance unlike CQ-initiated ones. ${ }^{39}$ MAPO delays the propagation stage of polymerization by diffusion-controlled mechanism. Also, it increases reaction temperature to increase molecular mobility and delays vitrification. However, in a systematic review on the role of photoinitiators and alternative initiators, it was found that they were the least effective in reducing shrinkage stress. ${ }^{8}$ 


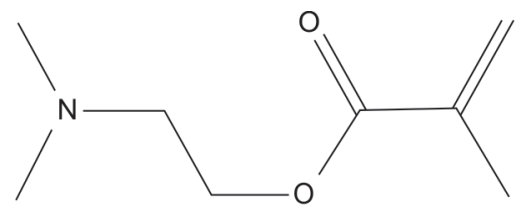

A DMAEMA

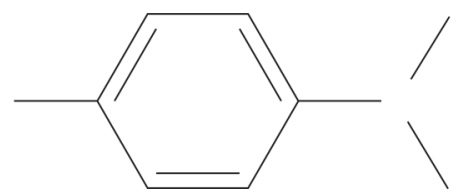

c

DMPT

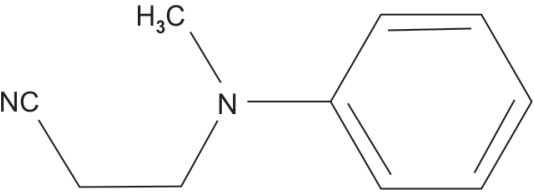

B

CEMA

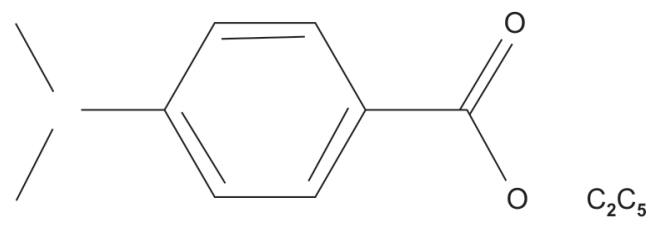

E DABE

Figs $27 \mathrm{~A}$ to E: Amine coinitiators/accelerators used in photopolymerization (Source: From Furuse AY, Mondelli J, Watts DC. Network structures of BisGMA/TEGDMA resins differ in DC, shrinkage-strain, hardness and optical properties as a function of reducing agent. Dent Mater 2011;27(5):497-506. DOI: 10.1016/j.dental.2011.02.007.)

\section{Alternative Coinitiators/Accelerators}

Different tertiary amines (Fig. 27), such as 2-dimethylaminoethyl methacrylate (DMAEMA), N,N-cyanoethylmethylaniline (CEMA), N,Ndimethyl-p-toluidine (DMPT), N,N-diethanol-p-toluidine (DEPT), and $\mathrm{N}, \mathrm{N}$-dimethyl-p-aminobenzoic acid ethylester (DABE), can be used with the camphorquinone in the photoinitiation. Of these, DEPT produced the least shrinkage while DMAEMA the highest. ${ }^{40}$

\section{Bulk-fill Composites}

These materials have modified initiators and fillers that enhance light transmission and hence reduce shrinkage stress. Under high compliance conditions, their low-viscosity versions worked as well as conventional packable composites. However, under low compliance, they reduce shrinkage stress greater than conventional low-viscosity materials. Hence, in a clinical situation, the cavity base which is a low-compliance area, bulk-fill low-viscosity composite can be used as a liner to reduce shrinkage stress. ${ }^{8}$

In a systematic review cum meta-analyses, comparing bulk-fill and conventional composites to assess their clinical behavior and physical-chemical properties, 32 studies evaluated polymerization shrinkage, 20 shrinkage stress, 21 cuspal defection, 26 microhardness, 44 marginal quality, and 11 randomized controlled trials. They found that regular viscosity bulk-fill was similar to conventional, whereas flowable bulk-fill showed less shrinkage than flowable conventional. However, it was noticed that across the studies, 10 different methods were used to measure shrinkage. Cusp deflection of bulk-fill was lower than conventional. Marginal gap formation was similar in both the groups. Also, clinical performance at 10 -year follow-up was similar. Only one study showed conventional to be better than bulk-fill at 6-year follow-up. ${ }^{41}$

\section{Ormocers}

These are "organically modified ceramics" and hence the name. Their organic matrix has alkoxysilane that has $\mathrm{RnSi}\left(\mathrm{OR}^{\prime}\right)(4-n)$ where the central core $\mathrm{Si}-\mathrm{O}$ is similar to ceramics and the $\mathrm{R}$ and $\mathrm{R}^{\prime}$ are multifunctional urethanes and thioethermethacrylates, respectively. They are essentially prepolymers with high molar mass and reduced double bonds in the $R$ and $R^{\prime}$ region that decrease shrinkage. They are claimed to have no residual unreacted monomers. ${ }^{42}$

In a recently published meta-analyses on direct posterior composite restorations comparing low-shrink vs methacrylatebased composites, authors reviewed 21 clinical studies, of which 4 compared ormocer, 13 silorane, 3 bulk-fill, and 1 In Ten S with conventional methacrylates. They were found to be largely similar, except in one article on silorane; methacrylates had better marginal adaptation at 18-month follow-up. In general, at 12 months, methacrylates outperformed all low-shrink materials. ${ }^{43}$

\section{Conclusion}

Clinically, polymerization shrinkage is assessed by measuring the marginal adaptation, marginal discoloration, secondary 
caries, retention, and postoperative sensitivity. However, the actual effects of shrinkage on clinical performance are not clearly elucidated. Adhesion plays a great role in counteracting shrinkage and shrinkage stress, and it is clinically impossible to say which of the two caused the actual failure. Hence, longevity of composite restorations may not be solely affected by polymerization shrinkage and shrinkage stress. The further confounding factors to these two criteria are the operator's experience, expertise, location of treatment, teeth characteristics, salivary composition, occlusal loading, contact points, and abusive dental habits. (The author prefers to use the term "abusive," rather than parafunctional, as the latter means habits that help function, while these habits do not help in any way for the masticatory function of teeth.) Of the many compositional modifications discussed above, modifying the resin matrix with thiocarbonates or allyl sulfides was found to be the best in reducing shrinkage and shrinkage stress. Filler modifications had moderate potential only in reducing shrinkage and shrinkage stress and that too when nanogel incorporation was used. Of the many modified coupling agents, functionalization with thiol-enes or hyperbranched oligomers was moderately capable of reducing shrinkage and shrinkage stress. None of the modifications in initiators or coinitiators and other agents like inhibitors and solvents were able to reduce shrinkage or shrinkage stress significantly. Though many laboratory investigations find the new and alternative low-shrink materials to be superior in reducing shrinkage and shrinkage stress, they all come with the downside of being expensive and requiring exceptional skill to sculpt them like conventional composites. Taken together, while it is necessary to reduce shrinkage and shrinkage stress, clinical prudence should prevail in choosing the right material as many other important factors dictate the ultimate success of a composite restoration. Since many new low-shrink materials have not been tested in long-term randomized controlled trials, it is highly recommended that such trials are done to understand their clinical relevance.

\section{References}

1. Braga RR, Ballester RY, Ferracane JL. Factors involved in the development of polymerization shrinkage stress in resin-composites: a systematic review. Dent Mater 2005;21(10):962-970. DOI: 10.1016/ j.dental.2005.04.018.

2. Patel MP, Braden M, Davy KWM. Polymerization shrinkage of methacrylate esters. Biomaterials 1987;8(1):53-56. DOI: 10.1016/01429612(87)90030-5.

3. Beigi Burujeny S, Atai M, Yeganeh H. Assessments of antibacterial and physico-mechanical properties for dental materials with chemically anchored quaternary ammonium moieties: thiol-ene-methacrylate vs. conventional methacrylate system. Dent Mater 2015;31(3):244261. DOI: 10.1016/j.dental.2014.12.014.

4. Schneider LF, Cavalcante LM, Silikas N. Shrinkage stresses generated during resin-composite application: a review. J Dent Biomech 2010;2010:131630. DOI: 10.4061/2010/131630.

5. Magali D, Delphine TB, Jacques D, et al. Volume contraction in photocured dental resins: the shrinkage-conversion relationship revisited. Dent Mater 2006;22(4):359-365. DOI: 10.1016/ j.dental.2005.03.014.

6. Calheiros FC, Sadek FT, Braga RR, et al. Polymerization contraction stress of low-shrinkage composites and its correlation with microleakage in class V restorations. J Dent 2004;32(5):407-412. DOI: 10.1016/j.jdent.2004.01.014.

7. Charton $C$, Falk V, Marchal $P$, et al. Influence of $T_{g}$, viscosity and chemical structure of monomers on shrinkage stress in light-cured dimethacrylate-based dental resins Dent Mater 2007;23(11):14471459. DOI: 10.1016/j.dental.2007.05.017.
8. Meereis CTW, Münchow EA, Oliveira da Rosa WL, et al. Polymerization shrinkage stress of resin-based dental materials: a systematic review and metaanalyses of composition strategies. J Mech Behav Biomed Mater 2018;82:268-281. DOI: 10.1016/j.jmbbm.2018.03.019.

9. Carioscia JA, Lu H, Stanbury JW, et al. Thiol-ene oligomers as dental restorative materials. Dent Mater 2005;21(12):1137-1143. DOI: 10.1016/j.dental.2005.04.002.

10. Moraes RR, Garcia JW, Barros MD, et al. Control of polymerization shrinkage and stress in nanogel-modified monomer and composite materials. Dent Mater 2011;27(6):509-519. DOI: 10.1016/j. dental.2011.01.006.

11. He J, Kopperud HM. Preparation and characterization of Bis-GMAfree dental composites with dimethacrylate monomer derived from 9,9-Bis[4-(2-hydroxyethoxy)phenyl]fluorene. Dent Mater 2018;34(7):1003-1013. DOI: 10.1016/j.dental.2018.03.007.

12. Ge J, Trujillo M, Stanbury J. Synthesis and photopolymerization of low shrinkage methacrylate monomers containing bulky substituent groups. Dent Mater 2005;21(12):1163-1169. DOI: 10.1016/ j.dental.2005.02.002.

13. Moszner N, Salz U. Recent developments of new components for dental adhesives and composites. Macromol Mater Eng 2007;292(3):245-271. DOI: 10.1002/mame.200600414.

14. Cramer NB, Stanbury JW, Bowman CN. Recent advances and developments in composite dental restorative materials. J Dent Res 2011;90(4):402-416. DOI: 10.1177/0022034510381263.

15. Soh MS, Yap AUJ, Sellinger A. Physicomechanical evaluation of lowshrinkage dental nanocomposites based on silsesquioxane cores. Eur J Oral Sci 2007;115(3):230-238. DOI: 10.1111/j.1600-0722.2007.00449.x.

16. Bailey WJ, Chou JL, Feng PZ, et al. Recent advances in free-radical ring-opening polymerization. J Macromol Sci-Chem 1988;A25 (5-7):781-798. DOI: 10.1080/00222338808053398.

17. Weinmann W, Thalacker C, Guggenberger R. Siloranes in dental composites. Dent Mater 2005;21(1):68-74. DOI: 10.1016/ j.dental.2004.10.007.

18. Byerley TJ, Eick JD, Chen GP, et al. Synthesis and polymerization of new expanding dental monomers. Dent Mater 1992;8(6):345-350. DOI: 10.1016/0109-5641(92)90016-6.

19. Stansbury JW. Synthesis and evaluation of novel multifunctional oligomers for dentistry. JDR 1992;71(3):434-437. DOI: 10.1177/00220345920710030201.

20. Magno MB, Nascimento GCR, Paula da Rocha YS, et al. Siloranebased composite resin restorations are not better than conventional composites - a meta analysis of clinical studies. J Adhes Dent 2016;18(5):375-386. DOI: 10.3290/j.jad.a36916.

21. Kolb HC, Finn MG, Sharpless KB. Click chemistry: diverse chemical function from a few good reactions. Angew Chem Int Ed 2001;40(11):2004-2021. DOI: 10.1002/1521-3773(20010601)40:11<2004: aid-anie2004>3.3.co;2-x.

22. Pfeifer CS, Wilson ND, Shelton ZR, et al. Delayed gelation through chain-transfer reactions: mechanism for stress reduction in methacrylate networks. Polymer 2011;52(15):3295-3303. DOI: 10.1016/j.polymer.2011.05.034.

23. Erhardt MCG, Goulart M, Jacques RC, et al. Effect of different composite modulation protocols on the conversion and polymerization stress profile of bulk-filled resin restorations. Dent Mater 2020;36(7):829837. DOI: 10.1016/j.dental.2020.03.019.

24. Lu H, Carioscia JA, Stansbury JW, et al. Investigations of step-growth thiol-ene polymerizations for novel dental restoratives. Dent Mater 2005;21(12):1129-1136. DOI: 10.1016/j.dental.2005.04.001.

25. Sowan N, Dobson A, Podgorski M, et al. Dynamic covalent chemistry $(D C C)$ in dental restorative materials: implementation of a DCC-based adaptive interface (AI) at the resin-filler interface for improved performance. Dent Mater 2020;36(1):53-59. DOI: 10.1016/ j.dental.2019.11.021.

26. Klee JE, Schneider C, Hölter D, et al. Hyperbranched polyesters and their application in dental composites: monomers for low shrinking composites. Polym Adv Technol 2001;12(6):346-354. DOI: 10.1002/ pat.116. 
27. Chung CM, Kim JG, Kim MS, et al. Development of a new photocurable composite resin with reduced curing shrinkage. Dent Mater 2002;18(2):174-178. DOI: 10.1016/s0109-5641(01)00039-2.

28. Leprince JG, Palin WM, Hadis MA, et al. Progress in dimethacrylatebased dental composite technology and curing efficiency. Dent Mater 2013;29(2):139-156. DOI: 10.1016/j.dental.2012.11.005.

29. He J, Söderling E, Lassila LVJ, et al. Preparation of antibacterial and radio-opaque dental resin with new polymerizable quaternary ammonium monomer. Dent Mater 2015;31(5):575-582. DOI: 10.1016/ j.dental.2015.02.007.

30. Wang X, Huyang G, Palagummi SV, et al. High performance dental resin composites with hydrolytically stable monomers. Dent Mater 2018;34(2):228-237. DOI: 10.1016/j.dental.2017.10.007.

31. He J, Garoushi S, Säilynoja E, et al. The effect of adding a new monomer "Phene" on the polymerization shrinkage reduction of a dental resin composite. Dent Mater 2019;35(4):627-635. DOI: 10.1016/j.dental.2019.02.006.

32. Podgórski M. Synthesis and characterization of acetyloxypropylene dimethacrylate as a new dental monomer. Dent Mater 2011;27(8):748754. DOI: 10.1016/j.dental.2011.03.014.

33. Ellakwa $A, C h o N$, Lee IB. The effect of resin matrix composition on the polymerization shrinkage and rheological properties of experimental dental composites. Dent Mater 2007;23(10):1229-1235. DOI: 10.1016/ j.dental.2006.11.004.

34. Atai M, Ahmadi M, Babanzadeh S, et al. Synthesis, characterization, shrinkage and curing kinetics of a new low-shrinkage urethane dimethacrylate monomer for dental applications. Dent Mater 2007;23(8):1030-1041. DOI: 10.1016/j.dental.2007.03.004.

35. Barszczewska-Rybarek IM. Characterization of urethanedimethacrylate derivatives as alternative monomers for the restorative composite matrix. Dent Mater 2014;30(12):1336-1344. DOI: 10.1016/j.dental.2014.09.008.
36. Ilie N, Hickel R. Investigations on a methacrylate-based flowable composite based on the SDRTM technology. Dent Mater 2011;27(4):348-355. DOI: 10.1016/j.dental.2010.11.014.

37. van Dijken JWV, Pallesen U. A randomized controlled three year evaluation of "bulk-filled" posterior resin restorations based on stress decreasing resin technology. Dent Mater 2014;30(9):e245-e251. DOI: 10.1016/j.dental.2014.05.028.

38. Song HB, Sowan N, Shah PK, et al. Reduced shrinkage stress via photo-initiated copper(I)-catalyzed cycloaddition polymerizations of azide-alkyne resins. Dent Mater 2016;32(11):1332-1342. DOI: 10.1016/ j.dental.2016.07.014.

39. Palin WM, Hadis MA, Leprince JG, et al. Reduced polymerization stress of MAPO-containing resin composites with increased curing speed, degree of conversion and mechanical properties. Dent Mater 2014;30(5):507-516. DOI: 10.1016/j.dental.2014.02.003.

40. Furuse AY, Mondelli J, Watts DC. Network structures of Bis-GMA/ TEGDMA resins differ in DC, shrinkage-strain, hardness and optical properties as a function of reducing agent. Dent Mater 2011;27(5):497-506. DOI: 10.1016/j.dental.2011.02.007.

41. Boaro LCC, Lopes DP, Caetano de Souza AS, et al. Clinical performance and chemical-physical properties of bulk fill composites resin-a systematic review and meta-analysis. Dent Mater 2019;35(10):e249e264. DOI: 10.1016/j.dental.2019.07.007.

42. Nicholson J, Czarnecka B. Composite resins. In: Materials for the direct restoration of teeth. Elsevier; 2016. p. 37-67. DOI: 10.1016/B978-0-08100491-3.00003-9.

43. Kruly PC, Giannini M, Pascotto RC, et al. Meta-analysis of the clinical behavior of posterior direct resin restorations: low polymerization shrinkage resin in comparison to methacrylate composite resin. PLoS One 2018;13(2):e0191942. DOI: 10.1371/journal.pone.0191942. 